\title{
Core Competency Education of Social Work Students: An Empirical Assessment Through Scale Development
}

\author{
Yu Guo (Corresponding author) \\ School of Labor and Human Resources, Renmin University of China \\ 59 Zhongguancun Street, Haidian District, Beijing, China
}

Tel: (86)-10-82502551; E-mail: graceguo@ruc.edu.cn

\begin{abstract}
Shuang Lu
Department of Social Work and Social Administration, The University of Hong Kong

Centennial Campus, Pokfulam Road, Hong Kong
\end{abstract}

Tel: (852)-3917-2080; E-mail: shuanglu@hku.hk

Chien-Chung Huang

School of Social Work, Rutgers, The State University of New Jersey

536 George Street New Brunswick, NJ 08901

Tel: (848)-932-5383 x 25383; E-mail: huangc@ssw.rutgers.edu

\section{Yuqi Wang}

School of Social Work, Rutgers, The State University of New Jersey

536 George Street New Brunswick, NJ 08901

E-mail: yw349@ssw.rutgers.edu

Yiwen Zhang

School of Labor and Human Resources, Renmin University of China

59 Zhongguancun Street, Haidian District, Beijing, China

E-mail: 2013201221@ruc.edu.cn 


\begin{abstract}
This study investigates how competency-based education and assessment prepare social work students to become competent professionals, with a quantitative examination of Chinese students' ( $n=332)$ core competencies. Factor analysis suggests that core competencies can be grouped into conceptual and professional dimensions. The regression results demonstrate that curriculum content satisfaction, preference for the social work major, field experience, and knowledge of career outlook are positively related to students' conceptual, professional, and comprehensive competencies. Gender and willingness for further study also relate positively to both conceptual and comprehensive competencies, and grade is positively associated with professional competency. These findings carry important implications for the competency-based approach to social work education in China.
\end{abstract}

Keywords: Competency, Social work education, China, Undergraduates

\title{
1. Introduction
}

For more than a decade, competency development has been a key concept of modern management in both the private and the public sector (Hjort, 2008). The concept of competency includes different types of qualifications in an understanding which spans a person's potential and practical abilities at one and the same time. In other words, it is a holistic concept that integrates all that is necessary to manage a given situation or challenge (Illeris, 2008). Competency-based education (CBE), an approach to teaching and learning that awards credit on the basis of mastery of clearly defined competencies or skills (Hoogveld, Paas, \& Jochems, 2005), has attracted renewed attention and application in higher education.

A clear definition of competency is required to guide implementers of competency-based initiatives in certain areas. Social work education has developed from training charity workers to training professionals in general service, clinical service, management and administration, community development, social policy, and program evaluation (Reid \& Edwards, 2006). To date, the interest in core competency of social work students is growing, and many social work institutions and programs have adopted this approach.

In terms of social work competency, the Council on Social Work Education (CSWE) (Note 1) in the U.S. developed the Educational Policy and Accreditation Standards (EPAS), which identified 10 core competencies as criteria for social work training outcomes. With the aim of evaluating the educational effectiveness of social work curriculum design and program implementation, this competency approach aims to examine social work students' integration of these competencies in practice with individuals, families, and communities (Council on Social Work Education, 2008). Each of the ten competencies constitutes related knowledge, values, skills, and measurable practice behaviors. An increasing number of social work programs highlight the CSWE core competencies in their training and evaluate training 
outcomes within relevant aspects.

Since the late 1990s, the increasing needs of vulnerable population and the expanding government-society collaboration, facilitated the professionalization of social work and its education in China (Xiong \& Wang, 2007). After 310 programs were initially established, the State Council approved the Master of Social Work programs in 2009, among which 104 are in operation today (China Association of Social Workers, 2015; Gao \& Yan, 2015).

When the Chinese government and universities undertook the challenge of reconstructing social work infrastructure, they looked to lessons learned in other countries to establish a set of curriculum and best practices. Throughout this period of revival, social work education in China has been significantly influenced by the Western social work philosophy, experiences, and knowledge. A number of Chinese social work educational programs are linked with their counterparts in the U.S. through the joint collaboration between the U.S. Council on Social Work Education (CSWE) and the China Association of Social Work Education (CASWE). With these global collaborations, competency-based approach has been applied in social work education and sometimes in the evaluation of learning outcomes of Chinese social work undergraduate programs.

However, social work in China is still exploring its paths of development, and existing studies lack empirical evaluations of students' core competencies (Lam \& Yan, 2015; Liu, Sun, \& Anderson, 2013). In this case, two essential questions are: What is the level of core competency among social work students in China? And what are the key factors affecting students' competency?

The current study aims to develop a conceptual framework to evaluate Chinese social work students' core competency. Through quantitative research, we use an adapted scale to examine the core competencies of Chinese social work undergraduate students. Our data source and measurement are based on the competency framework and existing evidence of factors related to social work student competency. We then use factor analysis and regression to further analyze students' core competency and associated factors. Finally, theoretical and practical implications are discussed.

\section{Competency-Based Education: Core Competency of Social Work Students}

\subsection{Competency-Based Learning Framework}

The framework is embedded in a competency-based approach to social work education. Competency is an integration of knowledge, skills, and attitudes (Carraccio et al., 2002). It is defined as individuals' ability of deliberately choosing from repertories of behaviors within the unique context of professional practice. Distinguished from knowledge and cognitive skills, competency is not only about knowing (knowledge) and performing (cognitive skills); it also requires strategy and personal ability (Kirschner et al., 2006).

As social work education shifts from knowledge-based to competency-based, more emphasis has been placed on the application of outcome and skills. CBE aims to provide students with the knowledge, skills, and attitudes to recognize and solve complex problems in their field of 
study or future work (i.e., authentic tasks; Keen, 1992). In this learning process, some elements are important for ensuring competency including pre-existing knowledge and skills, application of knowledge, assessment and feedback, and attitudes (Ragg, Piers, \& Kahn, 2012). Development of competencies begins with existing knowledge and skills; through application of existing knowledge and skills in practice, students receive feedback to increase their knowledge and improve skills. To gain competencies, students either choose suitable practical knowledge from their current knowledge pool, or replace existing knowledge and skills with new ones from practice and feedback (Kirschner, Vilsteren, Mummel, \& Wigman, 2006).

\subsection{Core Competency of Social Work Education}

Social work education in some countries is competency-based. In 2008, the Council on Social Work Education (CSWE), a national association that represents social work education in the United States, approved the Educational Policy and Accreditation Standards (EPAS). EPAS (2008) defines competencies as "measurable practice behaviors that are comprised of knowledge, values, and skills" (CSWE, 2008, p.3). The competency-based approach focuses on integration of values, knowledge, and skills, and in particular, how knowledge is transformed to practice. Ten core competencies were identified as the criteria for explicit social work curricula. Social work students are examined to measure their integration of these competencies in practice with individuals, families, and communities (CSWE, 2008).

According to CSWE (2008), the core competencies include: identifying as a professional social worker and conducting oneself accordingly; applying social work ethical principles to guide professional practice; applying critical thinking to inform and communicate professional judgments; engaging diversity and difference in practice; advancing human rights as well as social and economic justice; engaging in research-informed practice and practice-informed research; applying knowledge of human behavior and the social environment; engaging in policy practice to advance social and economic well-being and to deliver effective social work services; responding to contexts that shape practice; and engaging, assessing, intervening, and evaluating with individuals, families, groups, organizations, and communities.

\subsection{Social Work Competency Education in China}

Similar to the CSWE in the U.S., the China Association for Social Work Education (CASWE) is a professional organization that supports the development of social work education in China. Created in 1994 under the Ministry of Civil Affairs, the CASWE contributes to social work "academic exchanges, theoretical research, professional training, international cooperation, and advisory services" in China (CASWE, 2013; Fang, 2013). In 2004, CASWE provided guidelines to all degree-awarding social work programs in China and established ten foundation courses as a standardized curriculum, such as introduction to social work theory, casework, group work, community work, social administration, social policy, and introduction to social security (Xiong \& Wang, 2007).

Today, an increasing number of Chinese social work programs highlight these core 
competencies in their training and evaluate training outcomes within relevant aspects. Meanwhile, the collaboration between CSWE and CASWE laid the foundation for applying the core competencies approach to evaluate learning outcomes of social work undergraduates in China.

\section{Existing Evidence of Factors Influencing Core Competency of Social Work Students}

Along with the transitions in the social work profession, existing literature has extensively discussed approaches to enhance social work teaching and learning in different cultural settings, which include using applied learning projects for graduate social work students (Dubus, 2014), recognizing learning style preferences among undergraduate social work students (Williams, Brown, \& Etherington, 2013), and adapting social work education to the needs of emerging economies (e.g. South Africa; Collins \& Millard, 2013).

Certain scholars have discussed the role of social work competency. For example, Military Social Work has been discussed as an exemplar of how to teach social work competencies (Daley, Calson, \& Evans, 2015). Studies also identified four major factors that affect social work students' core competency: personal traits and experiences, curriculum satisfaction, field placement experiences, and future career outlook.

\subsection{Personal Traits and Experiences}

Personal traits, as well as life experiences that help shape these traits, may greatly influence social work students' learning outcomes and competencies. For instance, Hessenauer and Zastrow's (2013) interviews with 20 BSW students from CSWE-accredited programs found that most of them identified themselves as caring, nonjudgmental, having desire to help, patient, and empathetic; these traits were described as helpful for the students to dedicate themselves to a social work career. Learning the definition of these traits and the ways to develop these traits were also considered helpful for the participants to gain insights on professional development.

\subsection{Curriculum Satisfaction}

Curriculum satisfaction has significant impact on students' learning outcomes and competencies. Trainings that highlighted the importance of social work values and ethics, and approaches to develop professional values, were found crucial to students' transition to professional social workers. Class discussions that challenged different viewpoints, assignments that explored students' personal beliefs, and communications among people with different beliefs were found particularly helpful for social work students' personal and professional growth (Hessenauer \& Zastrow, 2013). Therefore, social work educators and employers have been calling for social work graduates and practitioners to be critically reflective. For instance, Adamson (2011) provided three models of program design and curriculum delivery for potential structural curriculum change that focuses on critical reflection.

In addition, learning environment (i.e., the implicit curriculum) is essential to learning outcome. A study of 534 social work students in the U.S. showed that those who experienced 
positive learning environments demonstrated greater professional identity as a social worker, greater self-perceived autonomy and independence, and stronger beliefs in their potential of making changes in communities (Peterson, Farmer, Donnelly, \& Forenza, 2014).

\subsection{Field Placement Experiences}

Field education is recognized as the signature pedagogy of the social work profession. As a key component of social work programs, field education integrates theory and practice, and prepares students with fundamental ways of thinking and performing with integrity (Council on Social Work Education, 2008). Field education is a critical element in the transfer of education to the workplace. Field instructors' availability and supervisory skills greatly contribute to students' positive field experiences (Hessenauer \& Zastrow, 2013), which in turn strengthen the connection between social work education and practice. Therefore, field experiences are essential to social work students' core competency.

\subsection{Career Outlook}

While many social workers are employed by the public, private, or nonprofit sector in countries such as U.S. and U.K., the career outlook for social work students in China is bleak. On the one hand, Chinese social work programs continue to expand enrollment without providing adequate faculty resources or field opportunities (Liu et al., 2013; Yuen-Tsang \& Wang, 2002). On the other hand, due to China's limited public recognition of the social work profession, potential clients and agencies are not yet accustomed to working with social workers, which significantly limited specialized social work employment opportunities (Chi, 2005; Liu et al., 2013). Consequently, social work graduates are forced to compete with students from other programs for very limited social work-related jobs. Difficulties in securing relevant jobs have forced many social work graduates to leave the profession (Yuen-Tsang \& Wang, 2002). The unpromising career outlook may also discourage social work students' motivation of learning and professional identity development.

A growing number of studies have discussed social work education in China (Gao \& Yan, 2015; Li, Han, \& Huang, 2013; Ma, 2014). The growing body of research highlights the importance of developing a new social work pedagogy more firmly grounded in empirical evidence (Wilson \& Kelly, 2010). However, there is a lack of a universally accepted instrument to measure Chinese social work students' core competency. Moreover, a paucity of literature has identified the effects of the factors that influence Chinese social work students' competency. To nurture the next generation of qualified social work professionals, it is imperative to examine students' competency levels and discuss measures to improve their competencies.

\section{Method}

\subsection{Sampling and Procedure}

Using a purposive sampling method, we surveyed eight Chinese universities to maximize variation of school features (i.e. location, university ranking) and student characteristics. The sampled universities were located in various geographic areas, including Beijing, Tianjin 
(northeast China), Jiangxi (central), Hebei (north), Shandong (East), and Guangdong (southeast). The universities also covered four ranks (see Note 2): top universities such as Renmin University of China (a 985-Project University, ranking first among these four categories), 211-Project universities such as Northern Electronic University (ranking $2^{\text {nd }}$ ), other first-class universities (ranking $3^{\text {rd }}$ ), and ordinary universities (ranking last). Faculty members of these universities distributed the questionnaires after their undergraduate classes from October 2013 to January 2014. Informed consent letters were attached with the survey questionnaire to ensure voluntary participation. In total, 400 respondents were recruited; 343 of them completed the survey. Excluding 11 cases with missing data on key variables, the final sample size used for data analysis was 332.

\subsection{Measurement}

Dependent variable: Core competency of social work students.

Our core competency measure was adapted from a 44-item questionnaire developed by Battle and Farmer (2010), which measures the ten CSWE core competencies for social work field placement and curriculum design. Each competency was measured by two to six items. All items were measured by a 5-point Likert scale, ranging from 1 'poor' to 5 'excellent'. Students were asked to self-rate each item.

As listed in Table 1, the original scale was shortened in our study due to resource limitation and inapplicability of certain items in China's context. Only items that were proved most relevant to China's social work education were included (Guo et al., 2014), such as "able to clearly define the professional role of social work." These items were selected through expert reviews, which are commonly used in questionnaire development (Fowler, 1995). The review process involved one professor, two assistant professors, two doctoral students, and six master students, all of whom are in social work programs and have extensive knowledge of the target population. With one to two highly representative items for each competency, twelve items were finally selected.

Following the guidelines proposed by Van de Vijver \& Hambleton (1996), the Chinese version of this scale was translated by a Chinese bilingual translator; an English speaker with good Chinese proficiency then back-translated these items. After the two translators compared the back-translation with the original scale and refined the translation through discussion, the final Chinese version was produced. A pilot study was then conducted among 46 social work students to test this scale's applicability in China; the average time for completing the scale was 20 minutes. The participants were asked to rate these items on a 5-point scale (1=extremely disagree to 5=extremely agree). The Cronbach's alpha was 0.86 , which indicated good internal reliability. 


\section{Macrothink \\ International Journal of Social Work \\ ISSN 2332-7278 \\ 2018, Vol. 5, No. 2}

Table 1. Measurement of ten core competencies

$\begin{array}{ll}\text { Dimension Definition Item(s) } & \text { Its }\end{array}$

1. Identify with Identify as a professional social worker and Attend to professional roles and profession conduct oneself accordingly. boundaries.

2. Ethical Understands and applies social work ethical Recognize and manage personal principles principles to guide professional practice. values in a way that allows professional values to guide practice.

3. Critical Applies critical thinking and communicates Distinguish, appraise, and thinking effectively.

integrate multiple sources of knowledge, including research-based knowledge, and practice wisdom.

4. Diversity Engages diversity and difference in practice.

Gain sufficient self-awareness to eliminate the influence of personal biases and values in working with diverse groups.

5. Human Advances human rights and economic Engage in practices that advance Rights justice. social and economic justice.

6. Research Engages in research-informed practice and practice-informed research.

6.1 Use practice experience to inform scientific inquiry.

6.2 Use research evidence to inform practice.

7. HBSE Applies knowledge of human behavior and the social environment (HBSE).

Critique and apply knowledge to understand person and environment.

8. Policy

Engages in policy practice to advance social Analyze, formulate, and advocate and economic well-being and to deliver effective social work services. for policies that advance social well-being. 
9. Context
Continuously discover, appraise, and attend to changing locales, populations, scientific and technological developments, and emerging societal trends to provide relevant services.

10.1 Collect, organize, and interpret client data to develop effective interventions.

10.2 Critically analyze, monitor and evaluate interventions.
10. Phases of Demonstrates effective professional practice treatment utilizing the skills of engagement, assessment, intervention and evaluation within the context of the services provided by the agency and specific assignments.

\section{Independent variable.}

In line with the literature, our independent variables comprised the four major factors related to student competency, including demographic and educational background (i.e., personal experience), curriculum quality and satisfaction, field experience, and career preference and outlook.

Demographic and educational background. Participants were asked to report their age, gender, family economic status (measured by a 3-point Likert scale, $3=$ above the average, $2=$ the average, $1=$ below the average), stage in the program ( $3=$ senior, $2=j u n i o r$, 1=sophomore), and school ranking. The school ranking was divided into four categories: first tier (985-Project), second tier (211-Project), third tier (other first-class universities), and the last tier.

Curriculum quality and satisfaction. Curriculum quality was measured by two variables: number of faculty members and whether there is an independent social work department. Curriculum satisfaction was measured by participants' perceived curriculum difficulty and satisfaction with curriculum content, which were rated on a 3-point Likert scale from 3 (very satisfied) to 1 (not satisfied). Preference for social work major was measured by a 3-point Likert scale from 3 (strong preference) to 1 (no preference).

Field experience was measured by the question "Do you have field placement experience" $(0=$ no, $1=$ yes $)$.

Career outlook. Four variables were used as a proxy for career outlook: preference for social work profession (measured by a 3-point Likert scale; $3=$ strong preference to $1=$ no preference), the possibility of choosing social work as a career (measured by a 3-point Likert scale; $3=$ highly possible to $1=$ not possible), knowledge of former graduates' career (which indicates a clear understanding of social work-related jobs), and willingness to attend graduate social work programs $(0=$ no, $1=y e s)$. 


\section{MInstitute"}

International Journal of Social Work

ISSN 2332-7278

2018, Vol. 5, No. 2

\subsection{Analytic Approach}

We first conducted Exploratory Factor Analysis (EFA) to categorize the existing factors and identify the underlying structures of the ten core competencies. In EFA the number of factors was determined according to those with eigenvalues $>1$, and by examining the scree plot. Multi-level regressions were then performed to examine which factors (demographic and educational background, curriculum quality and satisfaction, field experience, and career outlook) showed effects on students' core competencies. The Statistical Package for Social Sciences (SPSS) version 21.0 (Chicago, IL, USA) was used for data analysis.

\section{Results}

\subsection{Descriptive Analysis}

As shown in Table 2, in our final sample of 332 cases, the mean age of students was 20; most students were female (64.5\%). Students on average reported a high level of preference for social work profession, considered curriculum relatively not difficult, but had low satisfaction on curriculum content. In total, $83.1 \%$ of the students reported that they knew about former graduates' career choices. When asked about the future graduation plan, more than half of the students indicated they would not enter the job market until they have obtained the Master's degree.

Table 2. Descriptive statistics of the variables $(\mathrm{N}=332)$

Gender

Male

Grade

Sophomore 
Senior year

28.3

School Ranking

985-project School ( $1^{\text {st }}$ tier $) \quad 30.1$

211-project School (2 ${ }^{\text {nd }}$ tier $) \quad 14.8$

Other first-class school ( $3^{\text {rd }}$ tier $) \quad 28.3$

Other school $\left(4^{\text {th }}\right.$ tier $) \quad 26.8$

SW department $\quad 44.9$

$\begin{array}{lr}\text { Faculty number } & 19.35\end{array}$

Preference for social work major (1-3)

Curriculum difficulty (1-3)

Field experience

\subsection{Factor Analysis}

Table 3 presents the estimates of the latent structure of the core competencies from the exploratory factor analysis (EFA). The value of Kaiser-Meyer-Olkin Measure of Sampling Adequacy (KMO) was 0.87 , and Bartlett's test of sphericity was significant $\left(\mathrm{X}_{2}(45)=1199.6\right.$, $\mathrm{p}<0.001$ ), both of which indicated that our sample was suitable for factor analysis. The principal component analysis was adopted for extraction because our primary purpose was to calculate the composite scores for the factors. The Varimax with Kaiser Normalization was used for rotation. 


\section{Macrothink}

International Journal of Social Work

ISSN 2332-7278

2018, Vol. 5, No. 2

Two components were extracted (eigen value $>1$ ). We defined one component as conceptual competency, which emphasizes competencies on research and policy. Items of conceptual competencies included policy, context, research, phases of treatment, human rights, and human behavior in the social environment. The other component was defined as professional competency, which targets more on clinical practice. Items of professional competency included professional identity, ethical principles, critical thinking, and diversity.

These two competency components also correspond to the current social work education approaches in China. One traditional Chinese social science division highlights research and policy and adopts knowledge from social policy, social welfare, and sociology. Another division, which was introduced from social work in Hong Kong, highlights clinical practice and adopts psychology knowledge and skills. Chinese social work students can choose either conceptual or professional approaches.

The Cronbach's alpha for these two components was 0.826 for conceptual competency (6 items) and 0.749 for professional competency (4 items), both indicating good internal reliability. In addition, we averaged the scores of all items for each component as the overall level of conceptual $(M=3.065)$ and professional competency $(M=3.375)$.

Table 3. Factor loadings of core competencies scale $(\mathrm{N}=332)$

$\begin{array}{ll}\text { Conceptual } & \text { Professional } \\ \text { competency } & \text { competency }\end{array}$

8 Engages in policy practice to advance social and economic.829 well-being and to deliver effective social work services

9 Responds to contexts that shape practices in policy.812 practice

6 Engages in research-informed practice and.712 practice-informed research

10 Demonstrates effective professional practice utilizing the.696 skills of engagement, assessment, intervention and evaluation

7 Applies knowledge of human behavior and the social.502 environment 
1 Identify as a professional social worker and conduct oneself accordingly

2 Understands and applies social work ethical principles to guide professional practice

3 Applies critical thinking and communicates effectively

\subsection{Regression Analysis}

Table 4 lists the effects of independent variables on self-rated conceptual, professional, and comprehensive competency (calculated by the mean value of all the 10 competency scores), estimated by multilevel regressions. Model 1 and 2 show the predictors for conceptual and professional competency respectively. Model 3 presents the effects of demographic and educational background on the comprehensive competency only; other independent variables were added consecutively in model $4-6$. The collinearity diagnoses showed non-collinearity for independent variables $(\mathrm{VIF}<10)$.

As shown in Table 4, social demographic variables overall did not show significant effect, with $\mathrm{R}^{2}$ (and adjusted $\mathrm{R}^{2}$ ) at quite low levels. The curricular-related variables, field experience, and career outlook variables showed much greater influence: F values of Model 1 , $2,4,5$, and 6 were significant, suggesting the inclusion of these variables significantly improved the explanatory power of the regression model. About $11.9 \%$ of the variance of the conceptual competency was explained by model $1 ; 15.5 \%$ of the variance of the professional competency was explained by model 2 ; and $14.9 \%$ of the variance of the comprehensive competency was explained by model 6 .

Male students were found to have higher levels of conceptual and comprehensive competencies than female students. The impact of preference for social work major, field experiences, curriculum content satisfaction and knowing former graduates' career outlook was significant for conceptual competency, professional competency, and comprehensive competency. As students became senior, their professional competency overall improved. Students who were willing to pursue further social work education showed significantly higher conceptual and comprehensive competency. 


\section{Macrothink}

International Journal of Social Work ISSN 2332-7278 2018, Vol. 5, No. 2

Table 4. Multilevel regressions of conceptual professional and comprehensive competency scores $(\mathrm{N}=332)$

Conceptual Professional Comprehensive Competency

Model1 Model 2 Model 3 Model 4 Model5 Model6

\begin{tabular}{lllllll}
\hline Age & -0.013 & -0.039 & -0.042 & -0.043 & -0.039 & -0.024 \\
& $(0.044)$ & $(0.043)$ & $(0.040)$ & $(0.039)$ & $(0.038)$ & $(0.039)$ \\
Male & $0.284 * * *$ & 0.070 & $0.149 * *$ & $0.202 * * *$ & $0.195^{* * *}$ & $0.198^{* *}$ \\
& $(0.081)$ & $(0.079)$ & $(0.073)$ & $(0.072)$ & $(0.072)$ & $(0.071)$ \\
& & & & & & \\
Family economic status & -0.065 & -0.006 & 0.011 & -0.046 & -0.036 & -0.041 \\
& $(0.090)$ & $(0.088)$ & $(0.081)$ & $(0.080)$ & $(0.079)$ & $(0.079)$
\end{tabular}

Grade

$\begin{array}{lllllll}\text { Junior year } & 0.033 & 0.159 & 0.135 & 0.148^{*} & 0.107 & 0.084 \\ & (0.103) & (0.100) & (0.092) & (0.090) & (0.090) & (0.090) \\ \text { Senior year } & 0.020 & 0.245^{*} & 0.207^{*} & 0.257^{* *} & 0.152 & 0.110 \\ & (0.143) & (0.139) & (0.122) & (0.120) & (0.124) & (0.125)\end{array}$

School

985 school

$\begin{array}{llllll}-0.038 & -0.231 & 0.062 & -0.228 & -0.123 & -0.115 \\ (0.197) & (0.191) & (0.137) & (0.171) & (0.173) & (0.172)\end{array}$

211 school

$\begin{array}{llll}0.098 & -0.014 & 0.168 & 0.181\end{array}$

(0.209)

0.047

$(0.150) \quad(0.174)$

$(0.184)$

$(0.184)$

Other school

$0.043 \quad-0.056$

$0.077 \quad 0.029$

0.006

0.004

$(0.149)$

(0.145)

(0.131) (0.132)

(0.131)

(0.130)

SW department

$\begin{array}{ll}0.163 & 0.134 \\ (0.131) & (0.128)\end{array}$

$0.227 * *$

0.158

0.152

(0.131)

$(0.128)$

(0.114)

(0.116)

(0.115)

Faculty number

$-0.004 \quad-0.012 *$

$-0.012 * *$

$-0.008$

$-0.007$ 
$(0.007) \quad(0.007)$

Preference for SW major

$0.208 * * \quad 0.218 * *$

$(0.097) \quad(0.095)$

Curriculum difficulty

$0.092 \quad 0.068$

$(0.152)$

(0.148)

Curriculum satisfaction
$0.174 * *$
$0.157 * *$
$(0.081)$
(0.079)

$0.205^{*}$

$0.274 * * *$

(0.108)

$(0.105)$

$-0.006$

$(0.102) \quad(0.099)$

Possibility of SW career

$$
-0.011 \quad 0.059
$$

$(0.084) \quad(0.082)$

Knowledge of former $0.191 * \quad 0.280 * * *$

graduates' career

(0.102) (0.099)

Willingness for graduate $0.155^{* *} \quad 0.081$

$$
(0.078) \quad(0.076)
$$

Constant

$\begin{array}{llllll}2.349 * * & 3.290 * * * & 3.801 * * & 3.558 * * * & 3.214 * * * & 2.726 * * * \\ (0.991) & (0.965) & (0.813) & (0.857) & (0.857) & (0.869)\end{array}$

$\mathrm{R}^{2}$

0.119

0.155

0.022

0.100

0.122

0.149

Adjusted $\mathrm{R}^{2}$

0.069

0.106

$-0.002$

0.063

0.083

0.100

$\Delta \mathrm{R}^{2}$

0.21

0.027

$0.022 \quad 0.078$

0.022

0.027 


\section{Discussion, Implications, and Limitations}

Higher education is the key to "competency building" of an economy that desires to excel in innovation, cultivating a capable workforce equipped with essential skills and knowledge (Mok, 2013), with the goal of increasing employability and productivity. As China's social work education is expected to continue expanding for the next decade, it is vital to evaluate and increase the educational quality. Aiming to fill this research and practical gap, the current research applied the competency approach to measure the competency of social work undergraduates in China. Our findings carry important implications for research and practice of professional social work education in the Chinese context.

\subsection{Theoretical Implications}

Adapting the U.S. core competency approach in the Chinese context, this study empirically evaluates students' core competency. This study not only aims to introduce the competency-based educational and accreditation standards (CSWE, 2008) to China, it also explores measurable indicators for Chinese social work students' competencies. Our selected items showed good internal reliability in measuring students' core competencies.

The rapid growth of social work programs in China calls for the development of a conceptual framework to evaluate social work students' core competencies. This core competency approach and measurement show their applicability and predictive capacity for Chinese social work students, thus have the potential to be further integrated in social work curriculum design and learning outcome evaluation in China.

The factor analysis results suggest that these ten core competencies may be further grouped into professional and conceptual competencies, both of which are positively related to preference for social work major, curriculum content satisfaction, field experience, and knowledge of former graduates' career. Organizing the competencies into such taxonomy may help Chinese social work educators to advance their knowledge of student learning outcomes.

\subsection{Practical Implications}

The research findings carry important practical implications. First, our participants score relatively low in certain dimensions, such as "applies critical thinking and communicates effectively," "engage in research-informed practice and practice-informed research," and "respond to contexts that shape practices in policy practice." Therefore, these dimensions are worth more attention in social work education, possibly by cultivating student critical thinking, strengthen the research-practice link, and encouraging student participation in policy analysis or policy evaluation.

Second, unsatisfactory training prevents students from improving social work competencies. 
Many of the current social work curricula are in the lack of respect for student needs and interests, connection between theory and practice, and cultivation of ethical values (Shi, 2013). Moreover, Chinese social work curricula focus on textbook knowledge and theories, which contradicts the practice-oriented, contextual-based nature of the profession. These shortcomings may inhibit social work students' passion, initiative, and professional identity.

Third, curriculum content satisfaction, preference for social work major, field experience, and knowledge of former graduates' career are significant predictors for Chinese social work students' professional competency. This finding helps to diagnose the problems that social work students may encounter in their learning process. Meanwhile, it calls for Chinese social work educators to apply core competencies into curriculum design and advanced practice.

Notably, the variables "whether there is an independent social work department" and "number of faculty members" are not significant in predicting student competency, which suggests that curriculum quality is more essential than the size of the faculty in developing social work education. In addition, our findings suggest that China's social work education programs must consider students' willingness and preference for the major when making admission decisions. Having social work field experience is also key to students' competencies in all dimensions. The experience and quality of field supervisors are essential to the learning of field placement for students. This is especially vital to Chinese students as newly trained social work supervisors may lack experience on supervision (Lam \& Yan, 2015).

\subsection{Limitations and Implications for Future Research}

The current study has several limitations that warrant further research. First, we used a cross-sectional survey that might not reflect students' core competencies during their entire college experience. Future research can address this limitation by using a longitudinal study design. Second, our certain measures may not be the best proxy variables. For instance, we used twelve items to measure ten core competencies for Chinese students. Although the items showed high internal validity, future studies may use more items for each core competency to fully capture the concept of each competency. Third, although we increased the heterogeneity of our sample by selecting universities in different regions and rankings in China, the purposive sampling method limits the generalizability of our findings to the whole population. Last, our study used self-reported questionnaire to measure student core competencies, which may induce measurement errors. Based the conceptual framework in this study, future research may develop an competency measure through employee-report, educator-report, or participant observation.

Despite these limitations, this study addresses the lack of knowledge about social work student competency in China and provides practical implications to foster these competencies. One role of higher educational institutions is to produce a skilled and knowledgeable workforce that not only functions with minimal guidance, but also contributes effectively to potential employers (Abdul Karim, et al., 2012). What Chinese social work students obtain in school forms the foundation of their professional identity and workforce competency. As social problems and needs vary by region, the mechanisms by which social context affects the 
development of competency-based social work education merit further research.

\section{References}

Abdul Karim, A. M., Abdullah, N., Abdul Rahman, A. M. et al. (2012). A nationwide comparative study between private and public university students' soft skills, Asia Pacific Education Review, 13(3), 541-548. https://doi.org/10.1007/s12564-012-9205-1

Adamson, C. (2011). Getting the balance right: Critical reflection, knowledge and the social work curriculum. Advances in Social Work and Welfare Education, 13(1), 22-34.

Battle, D., \& Farmer, A. Y. (2010). Teaching diversity: Implications for implicit and explicit curriculum and the new CSWE education policy and accreditations standards. Paper presented at the $90^{\text {th }}$ Annual Meeting of the Southwestern Social Science Association. Houston, Texas.

Chi, I. (2005). Social work in China. International Social Work, 48(4), 371-379. https://doi.org/10.1177/0020872805053456

China Association of Social Workers (2015). 2014 National Report on Social Work Development. Retrieved from http://news.swchina.org/industrynews/2015/0316/21002.shtml

Collins, K., \& Milard, M. (2013). Transforming education in South Africa: comparative perceptions of a South African social work learning experience. Educational Review, 65(1), 70-84. https://doi.org/10.1080/00131911.2011.648168

Council on Social Work Education (2008). Educational Policy and Accreditation Standards (EPAS). Retrieved from https:/www.cswe.org/getattachment/Accreditation/ Standards-and-Policies/2008-EPAS/2008EDUCATIONALPOLICYANDACCREDITATION STANDARDS(EPAS)-08-24-2012.pdf.aspx

Council on Social Work Education. (2015). About CSWE. Retrieved from http://www.cswe.org/About.aspx

Council on Social Work Education (2017). 2016-2017 annual report. Retrieved from https://www.cswe.org/getattachment/About-CSWE/Annual-Reports/CSWE-Annual-Reports/ CSWE-Annual-Report-2017.pdf.aspx

Crowder, M. J., \& Hand, D. J. (1990). Analysis of Repeated Measures. London: Chapman and Hail.

Cui, Y. D. (1994). An Analysis of the Current Status and Development of Chinese Social Work Education. In Current Status, Challenge, and Background: Collected Papers from Asia and Pacific Social Work Education Seminar. Beijing: Beijing University Press.

Daley, G., Joan, C., \& Pinkie, E. (2015). Military Social Work as an Exemplar in Teaching Social Work Competencies, Journal of Social Work Education, 51(1), S76-S88. https://doi.org/10.1080/10437797.2015.1001288

Dubus, N. (2014). Applied Learning: A Project for Graduate Social Work Students. Social 
Work Education, 33(2), 254-270. https://doi.org/10.1080/02615479.2013.805193

Fowler, F. J. (1995). Improving survey questions: Design and evaluation. Thousands Oaks, CA: Sage.

Gao, J., \& Yan, M. (2015).Social work in the making: The state and social work development in China. International Journal of Social Welfare, 24, 93-101. https://doi.org/10.1111/ijsw.12089

Guo, Y., Guan, Y., Yang, X, Xu, J., \& Zhou, X. (2014). Career adaptability, calling and the professional competence of social work students in China: A career construction perspective. Journal of Vocational Behavior, 85, 394-402. https://doi.org/10.1016/j.jvb.2014.09.001

Hessenauer, S., \& Zastrow, C. (2013). Becoming a social worker: BSW social workers' educational experiences. The Journal of Baccalaureate Social Work, 18, 19-35.

Hjort, K. (2008). Competence Development in the Public Sector: Development, or Dismantling of Professionalism? Asia Pacific Education Review, 9(1), 40-49. https://doi.org/10.1007/BF03025824

Hoogveld, A. Paas, F., \& Jochems, W. (2005). Training higher education teachers for instructional design of competency-based education: Product-oriented versus process-oriented worked examples, Teaching and Teacher Education, 21, 287-297. https://doi.org/10.1016/j.tate.2005.01.002

Illeris, K. (2008). Competence Development - the key to modern education, or just another buzzword? Asia Pacific Education Review, 9(1), 1-4. https://doi.org/10.1007/BF03025820

Jia, C. (2008). Correcting misconceptions about the development of social work in China: A response to Hutchings and Taylor. International Journal of Social Welfare, 17, 98-101. https://doi.org/10.1111/j.1468-2397.2007.00536.x

Keen, K. (1992). Competence: What is it and how can it be developed? In J. Lowyck, P. De Potter, \& J. Elen (Eds.), Instructional design: implementation issues (pp. 111-122). Brussels: IBM International Education Center.

$\mathrm{Ku}, \mathrm{H}$., Yeung, S., \& Sung-Chan, P. (2005). Searching for a Capacity Building Model in Social Work Education in China. Social Work Education: The International Journal, 24(2), 213-233. https://doi.org/10.1080/0261547052000333144

Lam, C. M., \& Yan, M. C. (2015). Driving ducks onto a perch: the experience of locally trained Shenzhen supervisor. China Journal of Social Work, 8(2), 182-194. https://doi.org/10.1080/17525098.2015.1039169

Li, Y., Han, W-J., \& Huang, C-C. (2012). Development of social work education in China: Background, current status and prospect. Journal of Social Work Education, 48(4), 635-53. https://doi.org/10.5175/JSWE.2012.201100049

Lightfoot, E., \& Beltran, R. (2016). The GADE guide: A program guide to doctoral study in social work. St. Paul, MN: The Group for the Advancement of Doctoral Education in Social 
Work.

Retrieved

from

http://www.gadephd.org/Portals/0/docs/GADE\%20Guide\%20FINAL.pdf?ver=2017-01-19-0

95738-903

Liu, M., Sun, F., \& Anderson, S. G. (2013). Challenges in social work field education in China: Lessons from the western experience. Social Work Education, 32(2), 179-196. https://doi.org/10.1080/02615479.2012.723682

Mok, K. (2013). The quest for an entrepreneurial university in East Asia: impact on academics and administrators in higher education. Asia Pacific Education Review, 14, 11-22. https://doi.org/10.1007/s12564-013-9249-X

Peterson, N. A., Farmer, A. Y., Donnelly L., \& Forenza, B. (2014). Assessing the implicit curriculum in social work education: Heterogeneity of students' experiences and impact on professional empowerment. Journal of Teaching in Social Work, 34, 460-479.

Reid, P. N., \& Edwards, R. L. (2006). The Purpose of a School of Social Work-An American Perspective. Social Work Education: The International Journal, 25(5), 461-484. https://doi.org/10.1080/02615470600738817

Shi, B. (2013). New century: The dilemma confronting social work education in China. Chinese Education and Society, 46(6), 56-68. https://doi.org/10.2753/CED1061-1932460607

Van de Vijver, E., \& Hambleton, R. K. (1996) Translating tests: some practical guidelines. European Psychologist, 1, 89-99. https://doi.org/10.1027/1016-9040.1.2.89

Wilson, G. \& Kelly, B. (2010) Evaluating the effectiveness of social work education: preparing students for practice learning, British Journal of Social Work, 40, 2431-2449. https://doi.org/10.1093/bjsw/bcq019

Xinhua Net. (2013, August). China Has 300,000 Social Workers: Blue Book. Retrieved from http://news.xinhuanet.com/english/china/2013-08/13/c_132627691.htm

Xiong, Y., \& Wang, S. (2007). Development of social work education in China in the context of new policy initiatives: Issues and challenges. Social Work Education: The International Journal, 26(6), 560-572. https://doi.org/10.1080/02615470701456210

Yuen-Tsang, A., \& Wang, S. (2002). Tensions confronting the development of social work education in China: Challenges and opportunities. International Social Work, 45(3), 375-388. https://doi.org/10.1177/0020872802045003366

\section{Notes}

Note 1. As one of the earliest countries with systematic education in social work, the United States currently has 516 baccalaureate social work (BSW) programs, 254 master's social work (MSW) programs (Council on Social Work Education, 2017), and 82 doctoral programs (Lightfoot \& Beltran, 2016). A great number of baccalaureate and master's social work educational programs in the U.S. are accredited by CSWE nowadays. 
Note 2. Universities and colleges in China are divided into three classes. The first-class universities were considered best in their teaching, research, facility, and career outlooks. The 985-Project and 211-Project universities are those among first-class universities that have high reputation and quality. The 985-Project was launched in 1998 by the Chinese government, aiming to develop top universities; the 211-Project was launched earlier in 1995, aiming to develop universities with high teaching and research potentials to prepare skilled students. The criteria for the 985-Project are stricter than the 211-Project. The 985- and 211-Project universities were selected based on their teaching and research quality, national and local influence, and reputation both in China and overseas. The 985-Project universities were selected among 211-Project universities and they were bestowed the priority to receive funds and opportunities from government. Currently, there are thirty-nine 985-Project universities and one hundred and sixteen 211-Project universities in China.

\section{Copyright Disclaimer}

Copyright reserved by the author(s).

This article is an open-access article distributed under the terms and conditions of the Creative Commons Attribution license (http://creativecommons.org/licenses/by/3.0/). 